
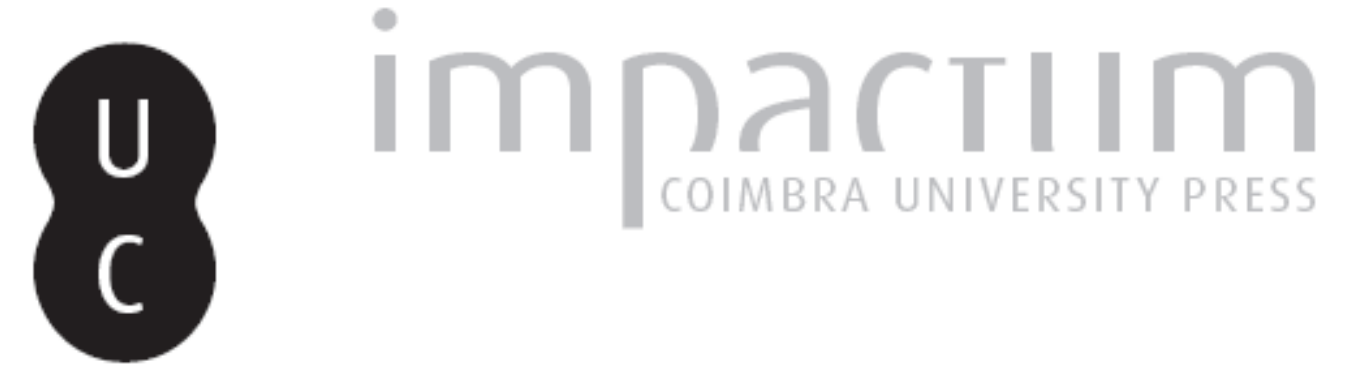

\title{
De uma inscrição encontrada em Peniche à historia de urna importante familia olisiponense
}

\author{
Autor(es): $\quad$ Venâncio, Rui
}

Publicado por: Imprensa da Universidade de Coimbra

URL

persistente:

URI:http://hdl.handle.net/10316.2/45377

DOI:

DOI:https://dx.doi.org/10.14195/1647-8657_39_7

Accessed : $\quad$ 26-Apr-2023 15:34:53

A navegação consulta e descarregamento dos títulos inseridos nas Bibliotecas Digitais UC Digitalis, UC Pombalina e UC Impactum, pressupõem a aceitação plena e sem reservas dos Termos e Condições de Uso destas Bibliotecas Digitais, disponíveis em https://digitalis.uc.pt/pt-pt/termos.

Conforme exposto nos referidos Termos e Condições de Uso, o descarregamento de títulos de acesso restrito requer uma licença válida de autorização devendo o utilizador aceder ao(s) documento(s) a partir de um endereço de IP da instituição detentora da supramencionada licença.

Ao utilizador é apenas permitido o descarregamento para uso pessoal, pelo que o emprego do(s) título(s) descarregado(s) para outro fim, designadamente comercial, carece de autorização do respetivo autor ou editor da obra.

Na medida em que todas as obras da UC Digitalis se encontram protegidas pelo Código do Direito de Autor e Direitos Conexos e demais legislação aplicável, toda a cópia, parcial ou total, deste documento, nos casos em que é legalmente admitida, deverá conter ou fazer-se acompanhar por este aviso.

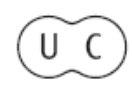


UNIVERSIDADE DE COIMBRA

FACULDADE DE LETRAS

\section{CONIMBRIGA}

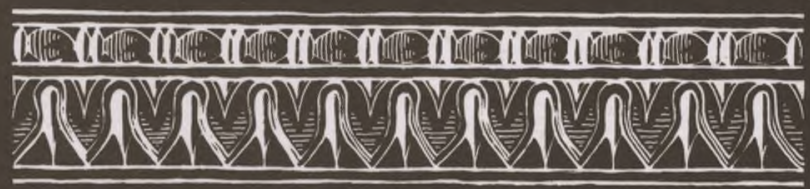

VOLUME XXXIX - 2000 
Rui VENÂNCIO

Licenciado em Arqueologia (Coimbra)

DE UMA INSCRIÇÃO ENCONTRADA EM PENICHE

À HISTÓRIA DE UMA IMPORTANTE FAMÍLIA OLISIPONENSE

"Conimbriga" XXXIX (2000) p. 259-273

RESUMO: Já conhecida desde o séc. XIX, a inscrição CIL II 5227 foi encontrada em Peniche, mas guarda-se no Museu do Louvre, em Paris. Narram-se, aqui, em síntese, as peripécias por que passou; dá-se a sua leitura correcta; e aponta-se a probabilidade de ser interessante testemunho da relação económica, familiar e social da população romana de Peniche com a de Olisipo, no momento em que escavações arqueológicas recentes proporcionaram a identificação de três fornos de cerâmica datáveis do Alto Império.

RÉSUMÉ: Connue depuis le XIX $\quad$ ème siècle, 1'inscription CIL II 5227 a été trouvée à Peniche, ville du litoral portugais au nord de Lisbonne, mais elle se conserve aux réserves du Musée du Louvre (MA 4105). On racconte ici Lhistoire de son déplacement; est présentée sa lecture correcte; et on la considère un intéréssant témoin des relations économiques, familiales et sociales de la population romaine de Peniche avec celle \& Olisipo, au moment oh des fouilles récentes ont mis au jour trois fours à céramique du Haut Empire.

Conimbriga, 39 (2000) 259-273 
(Página deixada propositadamente em branco) 


\section{DE UMA INSCRIÇÃO ENCONTRADA EM PENICHE À HISTÓRIA DE UMA IMPORTANTE FAMÍLIA OLISIPONENSE i}

\section{A estória de uma epígrafe}

Numa altura em que se debate a regionalização e se atribui especial importância ao património local, decidimos estudar a única epígrafe romana descoberta até à data em Peniche e que se encontra actualmente em França, no Museu do Louvre (CIL II 5227).

Trata-se de um cipo funerário, de basalto negro, encontrado em Peniche, na freguesia da Ajuda, no ano de 1858, pelo Sr. Pedro Cervantes de Carvalho Figueira. Ao passar, certo dia, num dos jardins do Morraçal da Ajuda, deparou-se com o cipo embutido nos alicerces de um muro e do qual lia à flor da terra a palavra: "POMPEIA".

Face a tal descoberta e, como refere numa carta enviada ao Duque de Bellune ${ }^{12}$, espicaçado pela curiosidade, tentou a todo o custo retirar a pedra, o que só lhe foi possível um ano após o achamento.

Ao examinar a peça na sua totalidade, Pedro Cervantes lê a seguinte inscrição:

$$
\text { P O M P E I A C }
$$

$$
\begin{aligned}
& \text { E.PACAT. HE.. } \\
& \text { L.TEREN TIVS F V R } \\
& \text { N V S M.R. I. T. E T I. T E } \\
& \text { RENTIVS R V F V S. } \\
& \text { E. C... }
\end{aligned}
$$

1 Trabalho elaborado no âmbito da cadeira de Epigrafia do curso de Arqueologia da FLUC, leccionada pelo Professor Doutor José d'Encarnação, a quem agradecemos todo o apoio prestado.

2 Transcrita parcialmente na obra, de Mariano Calado, Peniche na História e na Lenda, Peniche, 1968, 2a ed., pp. 63-64. 
Desta leitura ressalta Pedro Cervantes dois aspectos: em primeiro lugar, a palavra "POMPEIAC" - que, apesar de transcrever deste modo, julga dever ler-se "POMPEIAM", já que, segundo ele, Pompeia seria o nome dado pelos Romanos à então ilha de Peniche, por analogia com a conhecida cidade de Pompeia, na Campânia; por outro lado, sublinha a importância das últimas letras da inscrição, que julga significarem E(ra) C(aesaris), isto é, "era de César".

Tendo isso em conta e recorrendo aos relatos de Díon Cássio ${ }^{3}$, em que se alude ao facto de Júlio César, tendo vencido os Lusitanos, os haver obrigado a refugiar-se numa ilha junto à costa, Pedro Cervantes considerou a ilha de Peniche como sendo a ilha descrita e esta epígrafe a prova material da presença das tropas de César no território. E traduziu-a do seguinte modo:

Neste cabo de Pompeu, os Herminios foram vencidos pelas armas de L. Terêncio Rufo e J. Terêncio Rufo, militares romanos. Na era de César.

Esta seria, pois, a prova irrefutável de que a célebre campanha de Júlio César se teria desenrolado em Peniche, o que naturalmente conferia à localidade grande importância histórica. Tentou, por isso, que o cipo fosse solenemente implantado em lugar público. Contudo, tal não sucedeu, já que as autoridades locais pouca ou nenhuma importância deram à peça, tencionando até utilizá-la como laje em recinto que ia ser construído junto ao porto de desembarque. O facto terá deixado Pedro Cervantes bastante triste e irritado, a ponto de ter remetido a peça ao Duque de Bellune, seu conhecido, por intermédio da delegação francesa em Lisboa. Todavia, o destinatário último da peça não seria este aristocrata francês mas sim o imperador Napoleão III, a quem Pedro Cervantes terá oferecido a peça. Alguns anos depois, o monumento acabou por ser oferecido ao Museu do Louvre, em cuja colecção se encontra ainda actualmente ${ }^{4}$.

A inscrição voltará a ser publicada alguns anos mais tarde, em 1875, por Pinho Leal no seu Portugal Antigo e Moderno 5, e, em 1892, por Húbner no suplemento do vol. II do Corpus Inscriptionum Latinarum (= CIL II), baseando-se para tal na publicação da peça feita,

3 Díon Cássio, 37, 52-55, citado por Schulten, A., Fontes Hispaniae Antiquae (=FHA), V, Barcelona, 1925, pp. 12-13.

4 Calado, Mariano, Peniche na História e na Lenda, Peniche, 1984, 3ª ed., p. 65.

5 Leal, Pinho, Portugal Antigo e Moderno, vol. 6, p. 626.

Conimbriga, 39 (2000) 259-273 
em 1875, por C. Froehner, conservador do Museu do Louvre na sua obra Mélanges d'Épigraphie et d'Archéologie. Mais recentemente, é incluída em 1944, por Vieira da Silva na sua Epigrafia de Olisipo (= EO) e, em 1971, por J. Vives nas Inscripciones Latinas de la Espana Romana (= ILER) ${ }^{6}$.

$\mathrm{O}$ textos apresentados são, em tudo, semelhantes à reconstituição proposta por Hübner (CIL II 5227):

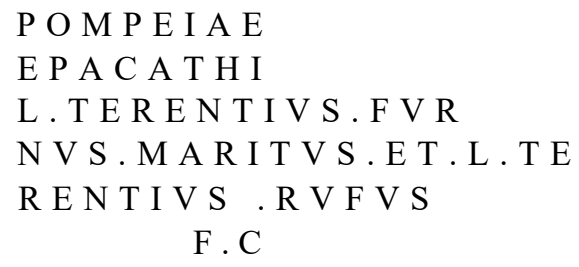

Tornaram-se, assim, claras as palavras presentes nas duas primeiras linhas da inscrição. Ao invés de "Pompeia, filha de Caio" e da enigmática E.PACAT seguida da suposta sigla funerária H.S.E, como defendia Pinho Leal, baseando-se na transcrição original de Pedro Cervantes, encontramos um nome claramente distinto: POMPEIA EPACATHI. Por outro lado, Hübner refere que o cipo foi encontrado "perto de Lisboa", sem, no entanto, precisar o sítio de achamento, algo que só ocorrerá mais de um século depois, através do contributo indispensável de Mariano Calado, aquando da pesquisa que levou a efeito para elaborar a monografia, já citada, Peniche na História e na Lenda.

Mariano Calado teve acesso a uma cópia da carta enviada por Pedro Cervantes ao Duque de Bellune, com um relatório pormenorizado acerca da peça. O passo seguinte, dado quando preparava a terceira edição, terá sido o de procurar a inscrição no CIL II, o que lhe forneceu duas informações bastante importantes: por um lado, identificava-se Peniche como sendo o local de proveniência da epígrafe e, por outro, deu-lhe a conhecer o seu paradeiro, o que lhe permitiu contactar o Museu do Louvre pedindo a sua correcta transcrição, o que lhe foi proporcionado pela conservadora Dr. ${ }^{a}$ Catherine Metzger, que, posteriormente, lhe terá enviado o seguinte texto ${ }^{7}$ :

6 EO n. $^{\circ}$ 131, p. 254; ILER 4457.

7 Confirmado pelo conhecido epigrafista Nõel Duval, da Sorbonne.

Conimbriga, 39 (2000) 259-273 


\author{
P O M P E I A E \\ E P A G A T H E \\ L. T E R E N T I V S F R \\ N V S.M A R I T. E T. L. T E \\ REN T I V S R V F V S \\ F . C
}

Mariano Calado, segundo indicação de Pedro Cervantes, considera-o um cipo funerário de basalto negro, acrescentando tratar-se de um tipo de rocha comum na brecha vulcânica da Papoa, situada não muito longe do local de achamento, o antigo Morraçal da Ajuda, em Peniche. Pesava cerca de $300 \mathrm{Kg}$, tinha $95 \mathrm{~cm}$ de altura, 45 de largura e 43 de espessura. Contudo, as dimensões apresentadas em $1984^{8}$ diferem bastante das que inicialmente se dá notícia: 45x42,5x8. Podemos, pois, concluir que a pedra foi desbastada, fundamentalmente na sua altura e espessura, provavelmente de modo a tornar-se mais facilmente arrumável, quase confundindo-se com uma placa epigrafada. Vale-nos, no entanto, a informação de Pedro Cervantes de que a inscrição se encontrava na parte superior da peça, que era um cipo.

Todavia, no que toca à análise externa da epígrafe, o comentário de Mariano Calado é lacónico, não referindo a profundidade e a dimensão das letras ou dos espaços interlineares.

Estas e outras informações foram, entretanto, conseguidas por Cardim Ribeiro que obteve do Museu do Louvre (MA 4105) a seguinte transcrição:

\author{
P O M P E I A E \\ E P A G A T H E \\ L. T E R E N T I V S F V R \\ NV S.MARIT.ET.L.TE \\ R E N T I V S.R V F V S. F. \\ F. C
}

POMPEIAE / EPAGATHE / Uncius) . TERENTIVS . FVR/NVS . MARITVS ET . L (ucius)TE/RENTIVS . RVFVS . F / F (aciendum). C(uraverunt)

${ }^{8}$ Data em que sai a $3^{\text {a }}$ edição de Peniche na História e na, sendo de considerar que estas informações tenham sido obtidas alguns anos antes.

Conimbriga, 39 (2000) 259-273 
A Pompeia Epagata, Lúcio Terendo Furno, marido, e Lúcio Terêncio Rufo, filho, mandaram fazer.

\section{O seu estudo}

Após esta breve dissertação sobre a estória da epígrafe, passemos ao seu estudo pormenorizado.

Trata-se, possivelmente, de um cipo funerário, de calcário (e não de basalto como anteriormente havia sido referenciado), encontrado no antigo Morraçal da Ajuda, em Peniche, segundo indicação de Pedro Cervantes. Originalmente, a inscrição teria $95 \mathrm{~cm}$ de altura, 45 de largura e 43 de espessura. Contudo, as dimensões actuais da inscrição diferem bastante das que inicialmente se dá notícia, coincidindo estas com as do campo epigráfico: $43 \times 44 \times 8$.

No que toca à análise externa da epígrafe, são várias as informações obtidas por Cardim Ribeiro - a quem agradecemos a amabilidade e a prontidão com que no-las disponibilizou. As letras possuem $5 \mathrm{~cm}$ de altura, sendo que os seus traços têm $2 \mathrm{~mm}$ de profundidade, e os espaços interlineares medem $1,5 \mathrm{~cm}$.

Por outro lado, em termos paleográficos, há a salientar a problemática inerente à nova leitura da palavra EPAGATHE (e não EPAGATHI, como até aqui). $\mathrm{O} E$ está por $\mathrm{AE}$, o que se explica pela frequência com que $\mathrm{AE}$ se grafa $\mathrm{E}$, por contaminação com a linguagem falada. Também a palavra MARITVS merece a nossa atenção: as letras $\mathrm{M}$ e A estão em nexo e o VS em letras mínimas e elevadas, o $\mathrm{S}$ quase em conexão com o E de ET.

No que toca à paginação, denota-se uma tendência para ordenar o texto logicamente segundo um eixo de simetria, o que não foi inteiramente conseguido, já que encontramos vocábulos cortados na translineação, embora em obediência às sílabas, letras em nexo e em tamanho mínimo e elevadas, aspectos resultantes da exiguidade do espaço.

O texto é inscrito em caracteres capitais quadrados monumentais, esguios, gravados de forma imperfeita, com os vértices inacabados.

Trata-se de uma inscrição de carácter funerário na qual, contudo, não é feita invocação aos deuses Manes, não por fractura da pedra (o que teria motivado o seu desaparecimento como, por vezes, acontece), mas sim porque, como iremos ver adiante, por motivos cronológicos essa invocação nunca existiu aqui. 
O epitáfio perpetua a memória de uma liberta, Pompeia Epagata. Dedicam-lhe o texto o marido, Lúcio Terêncio Furno, e o filho, Lúcio Terêncio Rufo. Este seria, sem dúvida nenhuma, filho do casal, já que além do mesmo nome, ostenta o mesmo preñóme de Lúcio Terêncio Furno e, como se sabe, era hábito entre os Romanos que o filho primogénito herdasse o preñóme do pai.

Em relação a Lúcio Terêncio Furno, há a destacar o facto de possuir um cognome que Iiro Kajanto ${ }^{9}$ considera como sendo tipicamente lusitano, o que nos levaria a tomar Lúcio Terêncio Furno como sendo um indígena romanizado. No entanto, se tivermos em conta que, na Península Ibérica e, neste caso específico, na Lusitânia estamos perante a única ocorrência deste cognome, o que atesta a sua raridade; por outro lado, se atendermos à análise linguística da palavra, que parece confirmar Furnus como sendo uma palavra latina e não lusitana ou de origem indoeuropeia, torna-se premente reformular as conclusões de Kajanto.

Com efeito, Iiro Kajanto relaciona Furnus com mobiliário; e se se tratar, ao invés, da palavra latina que significa forno? Será curial, com um único testemunho, considerar o cognome lusitano? E assim, face ao carácter latino do cognomen Furnus, estaremos na presença de um liberto e não de um indígena romanizado. A especificidade do cognome poderá indicar-nos a sua actividade profissional, que provavelmente seria a de oleiro, já que recentemente foram descobertos fornos romanos nas proximidades do local de achamento da epígrafe.

Todavia, a grande importância da inscrição advém da identificação da mulher, Pompeia Epagata. Inclinamo-nos a considerá-la uma liberta. O seu cognome, tipicamente grego, é extremamente raro na Península Ibérica: no CIL II encontramos apenas mais uma referência, em monumento de Mérida (CIL II 5273=ILER 6271):

D(iis) $\mathrm{M}$ (anibus) / VAL(eriae). APHRODISIAE / VXORI / VAL(erius) EPAGATHVS . B (ene) . / M(erenti) . F(aciendum) . C(uravit)

Aos deuses Manes. A Valéria Afrodísia, a esposa benemerente, Valério Epagato mandou fazer.

9 Kajanto, I, The Latin Cognomina, Roma, 1982, p. 348.

Conimbriga, 39 (2000) 259-273 
Dois libertos, Afrodísia e Epagato, duma família Valeria que, provavelmente, seria importante e conhecida em Emerita Augusta, já que se identifica em abreviatura.

Pompeia Epagata detinha, por conseguinte, o privilégio de ter um cognome extremamente raro e quase desconhecido na Península Ibérica. Qual seria, então, a sua origem? Com efeito, a importância destas duas famílias - a Pompeia e a Valéria - deverá ter radicado em intensa actividade económica assente no comércio, não apenas com a Península Ibérica ou com o Norte de África, mas também - e quiçá fundamentalmente - com a própria Península Itálica, centro redifusor de toda uma cultura helénica, com especial referência para a onomástica que rapidamente é adoptada pelas grandes famílias romanas e atribuída à criadagem servil.

A família Pompeia só poderá ter ganho esse elevado estatuto económico num grande centro urbano e comercial à época romana. Ora, as duas cidades romanas que mais próximo estão de Peniche são Eburobritium e Olisipo. Em relação a Eburobritium, pouco se sabe ainda desta cidade, já que a sua escavação sistemática apenas recentemente se efectuou, por intervenção de José Beleza Moreira. Por outro lado, também os testemunhos epigráficos, embora escassos, procedentes da zona, parecem não atestar a presença desta familia no termo de Eburobritium.

A sul de Peniche, encontramos Olisipo, comprovado centro urbano, este sim, com condições económicas, sociais, políticas e logísticas capazes de alicerçar e apoiar um importante comércio com a Península Itálica. E, ao analisarmos a epigrafia olisiponense, deparamo-nos com um importante núcleo de inscrições encontradas, no século passado, nos alicerces da muralha da Porta do Ferro, também conhecida por Arco de Nossa Senhora da Consolação ${ }^{10}{ }^{11}$. Alguns desses monumentos seriam provenientes da necrópole romana situada na actual Praça da Figueira, cuja datação aponta para uma longa utilização deste cemitério de incineração, entre o séc. I e o séc. IV da nossa era ${ }^{n}$. Neste núcleo regista-se um pequeno conjunto, datável da $2^{\text {a }}$ metade do séc. I, em que são mencionados indivíduos pertencentes a uma gens Pompeia, CIL II 244 por exemplo:

10 Inscrições referenciadas na Epigrafia de Olisipo de Vieira da Silva, pp. 131-168.

11 Heleno, M., "Estação lusitano-romana da Praça da Figueira", Ethnos, IV, 1965, pp. 305-308.

Conimbriga, 39 (2000) 259-273 
SEX(to) POMPEIO / Uucii) . F(ilio) . GAL(eria tribu) / [SJCAPVLAE / LIBER[T]I

A Sexto Pompeio Escápula, filho de Lúcio, da tribo Galéria, os libertos.

Há a salientar o cognome presente na terceira linha, que Vieira da Silva ${ }^{12}$ considera, e quanto a nós com razão, tratar-se de SCAPVLA, apesar de o $\mathrm{S}$ não ser visível. Um cognome tipicamente masculino, próprio de homens livres e de senadores ${ }^{13}$. Por outro lado, na última linha, Vieira da Silva preconiza a reconstituição de um $\mathrm{T}$ o que permite a leitura LIBERTE Contudo, não concordamos com a sua interpretação, pois considera Sexto Pompeio Escápula liberto, não obstante este se identificar como membro da tribo Galéria, a tribo da cidade de Olisipo. Sexto Pompeio Escápula seria, sem dúvida, um indivíduo extremamente rico, já que possuíra vários escravos, não um, dois ou três, mas um grupo considerável, a não permitir a sua discriminação na inscrição, provavelmente mandada lavrar como contrapartida testamentária à sua libertação.

O texto documenta o poder económico desta família, o que é inteiramente comprovado pela inscrição seguinte, também ela encontrada junto à Porta do Ferro (CIL II 243):

SEX(tas) POMPEI VS / FAVSTVS / H (7c) S (itus) E (st) / ET . F (ilia) . CAECILIA CALIMIS

Aquijaz Sexto Pompeio Fausto e afilha, Cecília Cálimis.

Estamos na presença de mais um liberto, Sexto Pompeio Fausto, já que não só dele se omite a filiação como também porque possui uma filha cujo cognome, etimológicamente grego, é revelador do seu passado de escravidão. Se tivermos em conta o hábito, instituído entre os Romanos, de se dar ao escravo agora liberto o preñóme do seu senhor, poderíamos pensar que o senhor de Sexto Pompeio Fausto seria, vero-

12 Silva, Vieira da, Epigrafia de Olisipo, Lisboa, 1944, p. 158.

13 Kajanto, Iiro, The Latin Cognomina, Roma, 1982, p. 225. 
simelmente, o já referido Sexto Pompeio Escápula, sendo Fausto um dos libertos mencionados na dita inscrição, funcionando a cronologia e a localização das inscrições como elementos comprovativos desta ligação. Aliás, Cecilia Cálimis para além de ostentar um cognome grego - que, tal como Epagata, é extremamente raro na Península Ibérica, existindo apenas mais um caso (CIL II 560) -, apresenta também como gentilicio o nome de uma das mais importantes famílias de Olisipo, cuja preponderância económica e social se encontra amplamente comprovada: a família Cecília ${ }^{14}$. É, pois, de considerar que tenha herdado este nome de sua mãe (como era habitual), antiga escrava da família.

Tendo em conta a ligação estabelecida entre libertos destas duas famílias, deduzir-se-á que a família Pompeia, tal como a família Cecília, gozaria de um grande poder económico e prestígio social em Olisipo. Isso poderemos definitivamente atestar através de mais uma inscrição (CIL II 214=ILER 3527), encontrada perto da Porta do Ferro:

[F]ABIVS . IVSTI . F(ilius) . GAL(eria tribu) / RVFVS . CLVNIENS(fs) (hedera) AN(norum) . XXXX (quadraginta) CAECILIA (hedera) SCAPVLAE . F (ilia). GEMINA / AN (norum) . XVIII (duodeviginti) . VXOR . OLISIPONE(n)S(^) / HOC . MAESOLIVM . SEMPRONIA / RVFINA . MATER . D $(e)$. SVO . FACIENDV(m) / CVRAVIT

Fábio Rufo, filho de Justo, da tribo Galéria, cluniense, de quarenta anos. Cecília Gémina, filha de Escápula, de dezoito anos, esposa, olisiponense. Semprónia Rufina, mãe, a expensas suas, mandou fazer este mausoléu.

Sem dúvida, uma inscrição bastante importante e curiosa, quer no que diz respeito à mensagem, quer no que diz respeito à paleografia.

Assim, uma provável fractura da pedra levou o praenomen e também a primeira letra de Fabius. Por outro lado, a filiação é indicada não pelo preñóme, como é normal, mas sim pelo cognome do pai,

${ }^{14}$ Basta consultar os índices da obra Epigrafia de Olisipo (Lisboa, 1944, pp. 277-278): embora já desactualizada, porque outras inscrições se encontraram, o certo é que impressiona o número de membros desta família referidos em inscrições.

Conimbriga, 39 (2000) 259-273 
à maneira indígena, o que nos permite datar a inscrição da segunda metade do séc. I. Encontramos também certas palavras com erros de grafia: OLISIPONES por OLISIPONENS, MAESOLIVM por MAVSOLEVM, tendo-se escrito a palavra talvez como se dizia, e, por fim, FACIENDV a que falta o $\mathrm{M}$ final.

$\mathrm{O}$ pai de Cecília Gémina chama-se Escápula. Se tivermos em consideração o local de achamento da inscrição, a sua datação e o facto de encontrarmos, tal como na inscrição de Sexto Pompeio Fausto, a referência à família Cecília, é, pois, de pensar que este Escápula poderá não ser mais do que Sexto Pompeio Escápula, constituindo esta inscrição a prova da existência de uma união familiar e, porventura, económica entre estas duas grandes famílias, que abarcava não só o senhor mas também os libertos.

Além disso, esta inscrição traduz também a tentativa, por parte da gens Pompeia, de estabelecer laços com a família Fábia, uma família, porventura, importante em Clunia Sulpicia (Coruña del Conde) e que, na segunda metade do séc. I, se vem estabelecer em Olisipo para, provavelmente, se dedicar à exploração mineira. Com efeito, se tivermos em conta o estabelecimento de uma notável comunidade cluniense em Três Minas (Vila Pouca de Aguiar), importante centro mineiro ${ }^{15}$, e as referências de autores antigos que falavam na exploração das areias do aurifer Tagus (Tejo) ${ }^{16}$, poder-se-á supor que a actividade económica desta família terá sido a exploração mineira, neste caso, aurífera.

O estabelecimento de laços familiares e económicos com a família Fábia é feito através do casamento de Gémina com Rufo, tendo esta casado extremamente cedo, pois morre com apenas dezoito anos, o que traduz, precisamente, um casamento inserido numa política de alianças familiares enquanto modo de consolidar monopólios, riqueza e prestígio social.

A família Pompeia teria sido uma familia bastante importante em Olisipo, pelo menos durante parte da segunda metade do séc. I d. C., o que é comprovável pelas ligações desta família com as gentes Cecília e Fábia e pelo facto de o "patriarca", Sexto Pompeio Escápula, surgir como senhor de vários escravos, provavelmente tornados libertos após

15 Alarcão, Jorge de, O Domínio Romano em Portugal, Mem Martins, 1988, $3^{a}$ ed.,p. 126.

16 Schulten, Adolf, Geografia y Etnografia Antiguas de la Península Ibérica, II, Madrid, 1963, pp. 245-246.

Conimbriga, 39 (2000) 259-273 
a sua morte. De entre estes libertos contar-se-iam, entre outros, Sexto Pompeio Fausto e, porventura, Pompeia Epagata, cuja inscrição, por não possuir referência aos deuses Manes, é datável da segunda metade do séc. I d. C. e, como tal, contemporânea das inscrições da gens Pompeia atrás mencionadas. Por outro lado, Pompeia Epagata possui - tal como Cecília Cálimis, liberta ligada à família Pompeia -, um cognome que é raro na Península Ibérica e que parece traduzir a apetência comercial desta família olisiponense.

Olisipo seria uma cidade marítima claramente virada para o comércio, como a Arqueologia tem demonstrado, albergando na sua elite social gentes como a Júlia, a Cássia e, claro está, a Cecília ${ }^{17}$. É esta actividade comercial que permite explicar a presença de vários libertos com cognomes gregos, alguns deles raros, como Cálimis ou Epagata, fruto de um intenso tráfico comercial, muito provavelmente com a Península Itálica, que terá feito circular não apenas produtos mas também ideias, ideias imbuídas de Helenismo e de que a adopção do onomástica grega é um bom exemplo.

Todavia uma questão se coloca: a que actividade comercial estaria ligada a família Pompeia? Para clarificar esta problemática teremos de, inevitavelmente, recorrer à Arqueologia.

Com efeito, recentemente, foi descoberto um forno romano situado não muito longe do local de achamento da inscrição. Estudos preliminares apontam para a sua laboração entre os séculos I e II d. C., levantando a hipótese de este forno ser contemporâneo da inscrição, possibilidade que assume especial importância se tivermos em conta a cognonímia mencionada, neste caso, o cognome Furnus.

Para além de cerâmica doméstica, esta olaria parece ter também produzido ânforas; ora, se tivermos em conta a vertente claramente marítima da região, em especial da então ilha de Peniche, e a informação transmitida por Hernâni de Barros Bernardo que evoca a existência de umas ruínas, hoje desaparecidas, identificando-as como "duas piscinas rectangulares" cada uma com "uns três metros de comprido por dois de largo" que lhe "faziam lembrar velhos pios de salga"18, poderemos preconizar a presença de um pequeno estabelecimento

17 José d'Encarnação in: Alarcão, Jorge de, O Domínio Romano, in Nova História de Portugal, Lisboa, 1990, p. 405.

18 Hernâni de Barros Bernardo, Marinhas ignoradas da Estremadura - as salinas de Peniche, Lisboa, 1966, p. 8. 
produtor de preparados piscícolas como o garum ou a salsamenta, condimentos que tanto deliciavam os Romanos justificando o estabelecimento na costa lusitana de importantes centros produtores, como na região de Tróia ou na costa algarvia, que alimentariam um rendível comércio com a Bética e com a própria Península Itálica.

Se a Arqueologia demonstrar que, na então ilha de Peniche, terá laborado um estabelecimento produtor de preparados piscícolas, que seria servido por uma olaria fornecedora de contentores anfóricos, poderemos aventar a hipótese bastante credível, tendo em conta as informações obtidas através da Epigrafia, de a família Pompeia se ter dedicado à produção e comercialização de preparados piscícolas, produção esta que seria envasada em ânforas produzidas por Lúcio Terêncio Furno e Lúcio Terêncio Rufo.

Face a esta apetência comercial da família Pompeia, assente neste possível comércio de preparados piscícolas, torna-se fácil explicar a existência de libertos desta família que ostentam cognomes gregos que na Península Ibérica assumem um carácter raro. Devemos preconizar a existência de um importante comércio de preparados piscícolas estabelecido entre a cidade de Olisipo e a Península Itálica que permitiu não apenas a divulgação dos preparados piscícolas lusitanos mas também, e no sentido inverso, a divulgação de ideias, usos e costumes, provenientes da metrópole, e de entre os quais se salienta a atribuição de cognonímia grega aos escravos, neste caso específico, de cognomes raros, pelo menos no contexto peninsular, o que parece demonstrar um contacto directo com negotiatores ou navicularii de proveniência itálica.

Com efeito, este tráfico comercial seria de tal modo rendível que justificaria a fixação em Olisipo de indivíduos provenientes da Península Itálica, como é, provavelmente, o caso de Cinnamidis (CIL II 216). Cinnamidis não é mais do que uma derivação rara do cognome Cinna (CIL II 3425 e 5525) que, por sua vez, era, originalmente, um preñóme etrusco tal como Blasio, Caepio, Cerco e Hispo ${ }^{19}$, prenomes que acabaram por, também eles, ser adoptados pela cognonímia latina.

O carácter raro e a proveniência geográfica deste cognome insinuam que Cinnamidis mais não seja do que um itálico, possivelmente proveniente da Etrúria, que a determinada altura se instalou em Olisipo para, porventura, se dedicar ao comércio.

19 Kajanto, Iiro, The Latin Cognomina, Roma, 1982, p. 42. 
Esta inscrição permite igualmente apercebermo-nos de que a difusão da cognonímia grega não se terá efectuado apenas através de uma intensa actividade comercial, mas também através de todo um processo de colonização assente na migração isolada e espontânea.

Em resumo, Pompeia Epagata seria uma liberta que teria alcançado este estatuto após a morte do seu senhor, Sexto Pompeio Escápula, tendo-se casado, posteriormente, com Lúcio Terêncio Furno, possivelmente também ele um liberto; dessa união nasceu Lúcio Terêncio Rufo. Pompeia Epagata terminou os seus dias em Peniche, velada pelo marido e pelo filho, longe de Olisipo e ainda mais longe da Grécia, terra que nunca conheceu mas que lhe legou a única coisa que era verdadeiramente sua - o cognome.

Partindo de uma simples inscrição encontrada em Peniche tornou-se possível levantar, um pouco, o véu que cobre a história da Lisboa romana, cujo conhecimento é relativamente diminuto face à sua abismal riqueza arqueológica que o progresso e a urbanização tendem, contudo, a ocultar e destruir. Perante esta realidade, a Epigrafia surge como importante auxiliar da Arqueologia, nomeadamente e neste caso específico para o conhecimento e compreensão da realidade social e económica da cidade. 


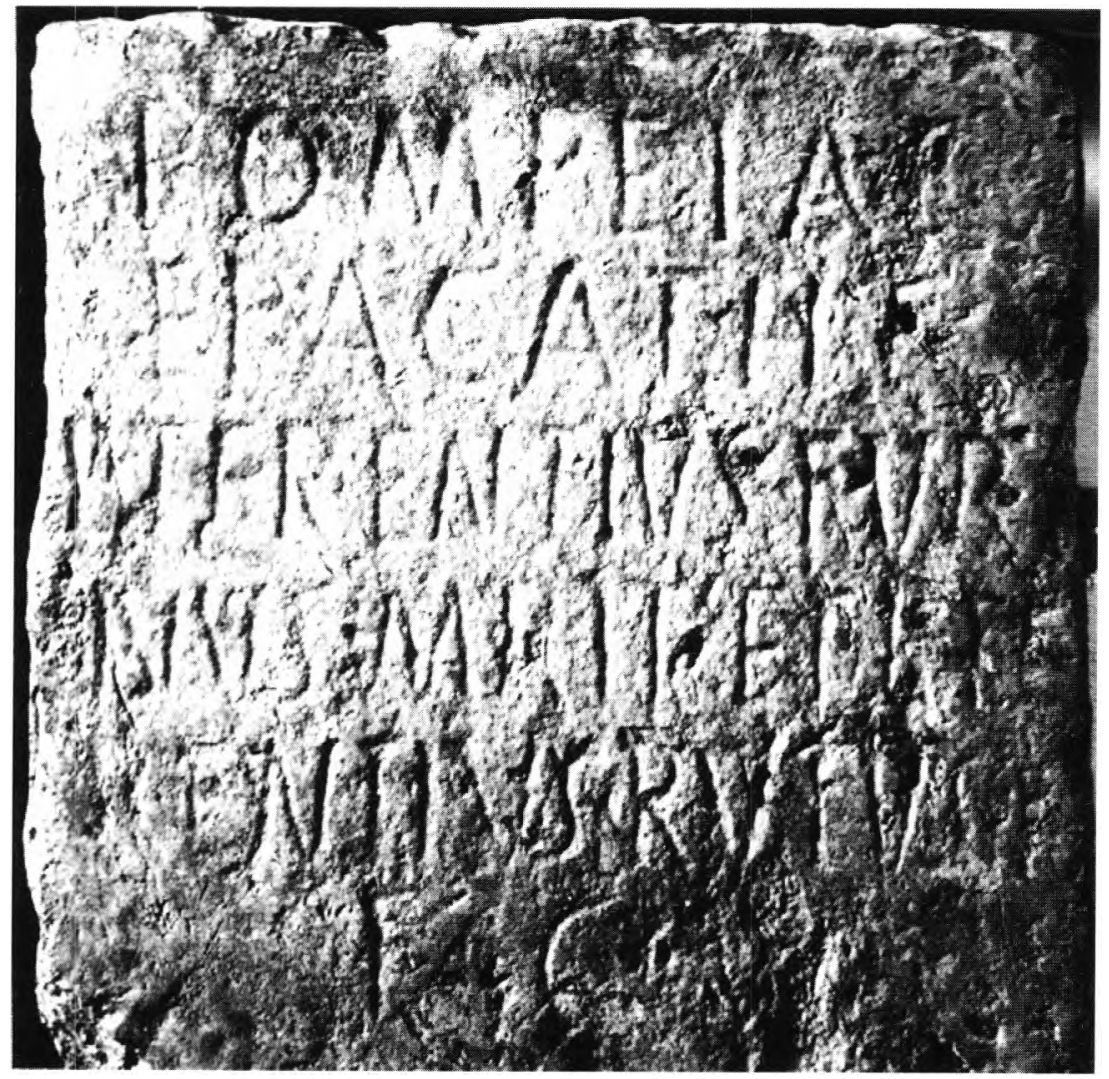

Fото 1 - Foto da inscrição de CIL II 5227, gentilmente disponibilizada pelo Dr. José Cardim Ribeiro, que a obteve junto dos Serviços do Museu do Louvre. Reproduzimo-la com a devida vénia: (C) Photo R.M.N., cliché MA 4105. 